\title{
Measurement System Analyses - Gauge Repeatability and Reproducibility Methods
}

\author{
Lenka Cepova $^{1}$, Andrea Kovacikova ${ }^{1}$, Robert Cep ${ }^{1}$, Pavel Klaput ${ }^{2}$, Ondrej Mizera ${ }^{1}$ \\ ${ }^{1}$ Department of Machining, Assembly and Engineering Metrology, Faculty of Mechanical Engineering, VSB-Technical \\ University of Ostrava, 17. listopadu 15/2172, 70833 Ostrava, Czech Republic, lenka.cepova@vsb.cz. \\ ${ }^{2}$ Department of Quality Management, Faculty of Metallurgy and Material Engineering, VSB-Technical University of \\ Ostrava, 17. listopadu 15/2172, 70833 Ostrava, Czech Republic.
}

\begin{abstract}
The submitted article focuses on a detailed explanation of the average and range method (Automotive Industry Action Group, Measurement System Analysis approach) and of the honest Gauge Repeatability and Reproducibility method (Evaluating the Measurement Process approach). The measured data (thickness of plastic parts) were evaluated by both methods and their results were compared on the basis of numerical evaluation. Both methods were additionally compared and their advantages and disadvantages were discussed. One difference between both methods is the calculation of variation components. The AIAG method calculates the variation components based on standard deviation (then a sum of variation components does not give $100 \%$ ) and the honest GRR study calculates the variation components based on variance, where the sum of all variation components (part to part variation, EV \& AV) gives the total variation of $100 \%$. Acceptance of both methods among the professional society, future use, and acceptance by manufacturing industry were also discussed. Nowadays, the AIAG is the leading method in the industry.
\end{abstract}

Keywords: GRR study approach, the average and range method, the honest GRR study.

\section{INTRODUCTION}

As R. Hart and M. Hart [1] claim, in a manufacturing process the perceived variation includes both the true, but unknown product variation (part to part variation) and the measurement system variation. When the perceived variation of a manufacturing process is too large, a measurement system study is needed to determine whether the improvement efforts should be made in the measurement process. The correct production process and part evaluation is conducted based on appropriately measured data and it is a technical necessity. Knowles a Vickers [2] highlight that the measured data are the core stones for the decision making process and these decisions are made under fully reliable circumstances. Therefore, in the serial production exist many standards, as e.g., IATF 16949 (automotive industry) [3], regulations and quality tools, e.g., ISO, QS - 9000 [4] that govern this problematic. Especially the requirements on serial production in the automotive industry are very strict. An important role plays quality planning by product development according to a set of techniques called APQP (Advanced product quality planning) [5]. The points of APQP manual subhead 4.2 - recommend for all processes in control plan their verification in accordance to measurement system analyses for specified measuring and monitoring gages. Hermans a Liu [6] claim that the measurement system analysis together with process failure mode and effect analysis (PFMEA) and control plan belong to the most important steps by new product development (NPD). The measurement system analysis is mainly conducted in accordance with:

- methods offered by the reference guideline of Chrysler, Ford and General Motors Company, called measurement system analyses (AIAG, MSA) [7],

- methods for evaluating the measurement process (EMP approach, Dr. Wheeler) [8],

- VDA5 methods - Measurement Process Qualification [9]. The detailed comparison of MSA and VDA5 approach is available, e.g., in thesis [10]. The overview of variability characteristic, such as stability, bias, linearity, repeatability and reproducibility are available for example in the publication of Dietrich and Schulze [11] or in the article of Kazerouni [12]. In the submitted article the attention is paid to the methods of measurement system variability analyses. The chosen methods are the range and average method (MSA, AIAG) [7] and the honest GRR study (EMP approach, Wheeler) [8].

Increase of the quality of manufactured products caused increase in the amount of research about techniques [30] used successfully to reduce the manufacturing defects [31]. 


\section{MEASUREMENT TASK DEFINITION}

The chosen measured part for the experiment purpose was the front cover of compact wheel loader (Fig.1.). The specified part is manufactured by thermoforming technology [13] on the machine GEISS. The raw material is from PMMA boards with thickness of $8 \mathrm{~mm}$. According to the drawing documentation the specified material thickness after thermoforming should be $4 \mathrm{~mm}$ with tolerance $-1.5 /+1.5 \mathrm{~mm}$. This request meets the defined surface tolerance. Beyond the surface tolerance the minimal part thickness of $3.5 \mathrm{~mm}$ is defined.

Parts for the measurement activities were collected gradually out of the manufacturing process. As the authors of Rolls-Royce guideline [14] highlight by conducting the measurement system analyses, it is important that chosen parts cover the full manufacturing tolerances. Therefore, one part from each production shift was collected in order to have ten parts available with full production tolerance coverage (GRR study requirement). Consequently, the parts were numbered on their inner surface from 1 to 10 . The measurement activities were conducted in the metrological laboratory with calibrated measurement devices (thickness gage) and three operators, who regularly conducted measurements of this specified part. As step one the first operator has measured all parts, then the second operator and at last the third operator.

All measurements were conducted with respect to the statistical measurement independence by hiding the measured part number. It means that operators did not know which part number they were measuring. The measured values were not written into the gage repeatability and reproducibility data collection sheet for measurement system analyses, but they were noted down in an Excel spreadsheet. The measured data overview is available in Table 1.
Table 1. Data of measurement II - plastic part [mm].

\begin{tabular}{|c|c|c|c|c|c|}
\hline \multicolumn{6}{|c|}{ Operator 1} \\
\hline Meas. & 1 & 2 & 3 & 4 & 5 \\
\hline 1. trial & 5.03 & 4.82 & 4.93 & 5.01 & 5.14 \\
\hline 2. trial & 5.02 & 4.94 & 4.81 & 5.03 & 5.03 \\
\hline 3.trial & 5.01 & 4.84 & 4.93 & 5.00 & 5.02 \\
\hline Meas. & 6 & 7 & 8 & 9 & 10 \\
\hline 1. trial & 5.23 & 4.89 & 5.13 & 4.93 & 4.97 \\
\hline 2. trial & 5.21 & 4.87 & 5.02 & 4.91 & 4.98 \\
\hline 3.trial & 5.23 & 4.92 & 5.03 & 5.01 & 4.95 \\
\hline \multicolumn{6}{|c|}{ Operator 2} \\
\hline Meas. & 1 & 2 & 3 & 4 & 5 \\
\hline 1. trial & 5.13 & 4.78 & 4.83 & 4.99 & 5.03 \\
\hline 2. trial & 5.03 & 4.79 & 4.82 & 4.99 & 5.03 \\
\hline 3.trial & 5.03 & 4.78 & 4.94 & 4.98 & 5.03 \\
\hline Meas. & 6 & 7 & 8 & 9 & 10 \\
\hline 1. trial & 5.22 & 4.88 & 5.00 & 5.02 & 5.00 \\
\hline 2. trial & 5.11 & 4.89 & 5.00 & 4.94 & 5.03 \\
\hline 3.trial & 5.22 & 4.78 & 4.98 & 4.92 & 5.02 \\
\hline \multicolumn{6}{|c|}{ Operator 3} \\
\hline Meas. & 1 & 2 & 3 & 4 & 5 \\
\hline 1. trial & 5.03 & 4.77 & 4.82 & 5.02 & 4.99 \\
\hline 2. trial & 5.04 & 4.78 & 4.82 & 5.14 & 5.03 \\
\hline 3.trial & 5.13 & 4.89 & 4.80 & 5.01 & 5.1 \\
\hline Meas. & 6 & 7 & 8 & 9 & 10 \\
\hline 1. trial & 5.22 & 4.92 & 5.02 & 4.94 & 5.03 \\
\hline 2. trial & 5.22 & 4.94 & 5.14 & 4.92 & 5.01 \\
\hline 3.trial & 5.24 & 4.94 & 5.02 & 4.91 & 5.14 \\
\hline
\end{tabular}

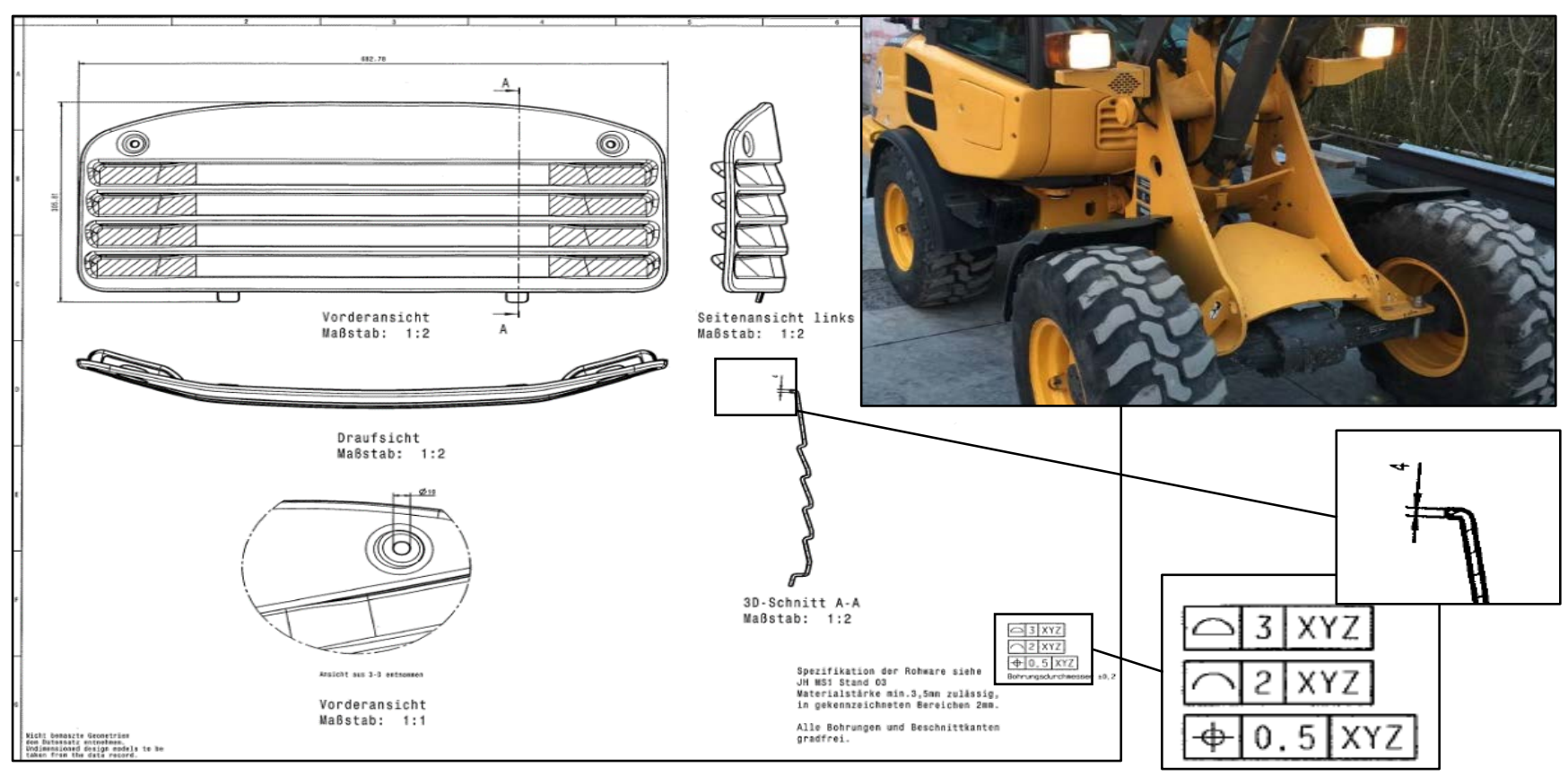

Fig.1. Drawing cut out - a plastic part of compact wheel loader cabin front area. 


\section{Average AND RANGE METHOD}

The average and range method $(\bar{X}, \bar{R})$ is a method for measurement system evaluation of continues scale. The results of this method have to be interpreted based on graphical and numerical results as it is highlighted by Klaput [9]. The advantage of this method is in its possibility to fracture the variability components to:

- Measurement gage variability (repeatability),

- Operator variability (reproducibility).

The disadvantage of this method is that it does not take into consideration the operator and part or measurement gage interactions. The mentioned statement is also confirmed in the submitted article of Healy and Wallce [15]. The method progress consists of few logically followed steps. At the beginning is evaluated the statistical process stability from repeatability point of view by repeated measurements based on average chart and range chart. The detailed examination of both graphs belongs to the graphical outputs of the average and range method, which are available, e.g., in the statistical software Minitab [16]. After the statistical process stability is confirmed, the measurement system evaluation is continued by numerical step by step evaluation.

At first, the measurement repeatability EV is estimated according to (1).

$$
E V=\hat{\sigma}_{p e}=\frac{\overline{\bar{R}}}{d_{2}}
$$

where,

$\overline{\bar{R}}$ - the average variation range of all operators' repeated measurements for all parts,

$d_{2}$ - correction factor for values link to the distribution of average variation (see appendix C in MSA, AIAG guideline) [7]. It is necessary to look for this coefficient in the penultimate line, whereas $\mathrm{m}=$ number of repeated measurement trials. For $\mathrm{m}=3 \rightarrow d_{2}=1.69257$.

In the next step, the measurement reproducibility $\mathrm{AV}$ is calculated according to (2).

$$
A V=\hat{\sigma}_{o}=\sqrt{\left(\frac{\bar{R} D I F F}{d_{2}}\right)^{2}-\frac{o}{o . n . r} * E V^{2}}
$$

where

$\bar{R}_{\text {DIFF }}$ - is the variation range of repeated measurement for each measured part by single operator calculated according to (3).

$\mathrm{r}$ - number of measured parts,

$\mathrm{n}$ - number of repeated measurement trials,

$\mathrm{o}$ - number of operators,

$d_{2}$ - correction factor for values link to the distribution of average variation (see appendix C in MSA, AIAG guideline) [7]. It is necessary to look for this coefficient as $g$ (number of subgroups) $=1$ (fixed factor) and $m$ (subgroup range) = number of operators (variable). For $\mathrm{m}=3$ (conducted measurement task) $\rightarrow d_{2}=1.91155$.

$$
\bar{R}_{D I F F}=\left|\bar{R}_{M A X}-\bar{R}_{M I N}\right|
$$

where,
$\bar{R}_{M A X}-$ largest arithmetical average for one of the three operators,

$\bar{R}_{M I N}$ - smallest arithmetical average for one of the three operators

In the following steps, there is the possibility to process with evaluation of combined gage the repeatability and reproducibility GRR according to (4).

$$
\mathrm{GRR}=\hat{\sigma}_{e}=\sqrt{E V^{2}+A V^{2}}
$$

The calculated GRR value does not have any ability. The measurement system suitability (\% GRR - percentage of repeatability and reproducibility) is possible to evaluate just after the comparison of repeatability and reproducibility (measurement system variability) with the total variability TV (process variability), that is calculated by (5).

where,

$$
T V=\hat{\sigma}_{x}=\sqrt{G R R^{2}+P V^{2}}
$$

PV - part variability calculated according to (6):

$$
P V=\hat{\sigma}_{p}=\frac{R_{p}}{d_{2}}
$$

where,

$\mathrm{Rp}$ - the variation range from the measurement of arithmetic mean of the individual repeats for the individual subgroups of the parts.

$d_{2}$ - correction factor for values link to the distribution of average variation (see appendix C in MSA, AIAG guideline) [7]. It is necessary to look for this coefficient as g (number of subgroups) $=1$ (fixed factor) and $m$ (subgroup range) $=$ number of measured parts (variable). For $m=10$ (No. of measured parts) $\rightarrow d_{2}=3.17905$.

The penultimate step after the TV value calculation is the calculation of measurement system suitability indicator \% GRR - gage repeatability, \% AV - reproducibility, and \% PV - product variability. The \% GRR - value of repeatability and reproducibility is calculated according to (7), what is the proportion of combined repeatability and reproducibility divided by total variability and multiplied by 100 . The value called \% GRR is interpreted as the percentage of total variation that redounds to the combined repeatability (EV) and reproducibility (AV)

$$
\% G R R=100 \cdot \frac{G R R}{T V}
$$

The percentage representation of repeatability \% EV is calculated according to (8), where the parameter called \% EV refers to the percentage value of total variability that redounds to the equipment variability.

$$
\% E V=100 \cdot \frac{E V}{T V}
$$

The percentage representation of the second variability component - reproducibility \% AV is calculated according to (9), where the parameter called \% AV refers to the percentage value of total variability that redounds to the operator variability. 


$$
\% A V=100 \cdot \frac{A V}{T V}
$$

As the second to the last one the percentage representation of product variability \% PV is calculated according to (10). The parameter called \% PV refers to the percentage value of total variability that redounds to the part to part variability.

$$
\% P V=100 \cdot \frac{P V}{T V}
$$

As the last step in this method the ndc parameter (number of district categories) is calculated, where by this calculation is defined the number of district categories that can be distinguished by the measurement system. AIAG [7] and also Minitab guideline [16] calculates the ndc parameter according to (11).

$$
n d c=1.41 \cdot \frac{P V}{G R R}
$$

The outcome for average and range method is about making a decision whether the measurement system is acceptable, conditionally acceptable or not acceptable based on the decision making matrix for measurement system evaluation based on two criteria (AIAG approach [7]). The first criterion is \% GRR, see Table 2., and the second criterion is ndc parameter, see Table 3. On the border values (\% GRR, ndc) are also different angles of view as stated by Dietrich and Schulze [11].

Table 2. The border values of \% GRR [7].

\begin{tabular}{|c|l|}
\hline$\% G R R<10 \%$ & $\begin{array}{l}\text { Acceptable measurement system. } \\
\text { The measurement system provides } \\
\text { reliable information about the } \\
\text { process changes. }\end{array}$ \\
\hline $\begin{array}{l}10 \%<\% G R R \\
<30 \%\end{array}$ & $\begin{array}{l}\text { Conditionally acceptable } \\
\text { measurement system. It can be used } \\
\text { for some applications. }\end{array}$ \\
\hline$\% G R R>30 \%$ & $\begin{array}{l}\text { Not acceptable measurement } \\
\text { system. The measurement system } \\
\text { does not provide reliable } \\
\text { information about the process } \\
\text { changes. }\end{array}$ \\
\hline
\end{tabular}

Table 3. The border values of ndc [7].

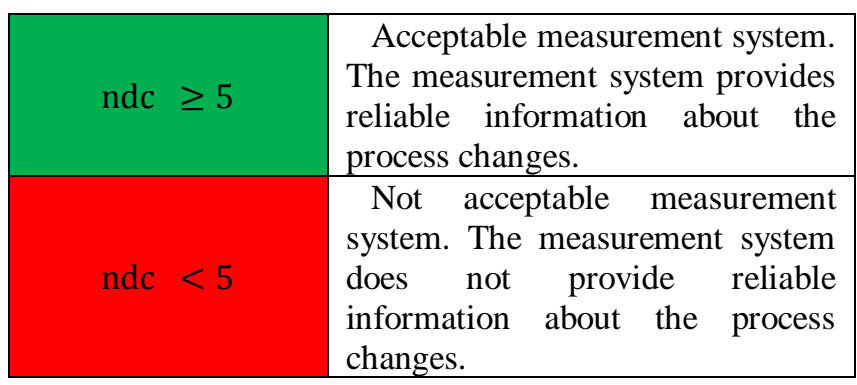

\section{THE HONEST GRR STUDY (EMP)}

The honest GRR study belongs to the EMP methods [8] Evaluating the measurement process, what are the methods for measurement system evaluation. As G. Knowlers [17] highlights a variability reduction, it belongs today to the interest of the manufacturing companies. The EMP method bases were developed in the 80's by the American statistician and awarded quality expert Dr. Wheeler [18]. A part of the EMP methods is also the honest GRR study. The method is nowadays a part of debates among professionals, e.g. [19], [20], there exist qualification courses for its introduction and implementation (mainly in the USA) and EMP macros are available by some statistical software as, e.g. the SAS7QC software [22]. In order to evaluate the consistency, this method uses regulation charts that can detect bias between operators (reproducibility) or inconsistency between operators. For measurement error evaluation the honest GRR study based on the Fisher intraclass correlation coefficient is used. By the value of intraclass correlation coefficient the measurement system is divided into four groups (class monitors): first, second, third, and fourth [8]. Each single monitor class is characterized by its ability to attenuate the production process signals in regular chart, the ability to detect shift and to detect the production process improvement. From this point of view the individual class monitors are characterized according to three factors [22]:

- Attenuation of process signals,

- Chance to detect a shift,

- Measurement system ability to track the process improvement.

Here applies the rule, the higher number of class monitor there is (max. class monitor 4), the greater percentage of variance there is due to measurement system variability. The overall systematic review of four class monitors and their factor characteristics is shown in Table 4.

\begin{tabular}{|c|c|c|c|c|}
\hline 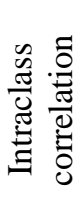 & 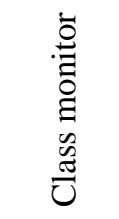 & 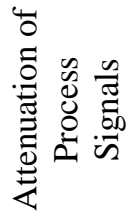 & 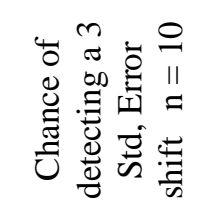 & 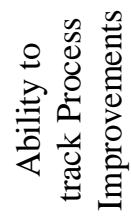 \\
\hline $\begin{array}{c}0.80 \\
- \\
1.00 \\
\end{array}$ & First & $\begin{array}{l}\text { Less } \\
\text { then } \\
10 \%\end{array}$ & $\begin{array}{c}\text { More than } \\
\text { 99\% with rule } \\
\text { one }\end{array}$ & $\begin{array}{c}\text { Up to } \\
\mathrm{C}_{\mathrm{p} 80}\end{array}$ \\
\hline $\begin{array}{c}0.50 \\
- \\
0.80\end{array}$ & Second & $\begin{array}{c}10 \% \\
- \\
30 \% \\
\end{array}$ & $\begin{array}{c}\text { More than } \\
88 \% \text { with rule } \\
\text { one }\end{array}$ & $\begin{array}{c}\text { Up to } \\
\mathrm{C}_{\mathrm{p} 50}\end{array}$ \\
\hline $\begin{array}{c}0.20 \\
- \\
0.50\end{array}$ & Third & $\begin{array}{c}30 \% \\
- \\
55 \% \\
\end{array}$ & $\begin{array}{c}\text { More than } \\
91 \% \text { with rule } \\
1 .-4 .\end{array}$ & $\begin{array}{l}\text { Up to } \\
\mathrm{C}_{\mathrm{p} 20}\end{array}$ \\
\hline $\begin{array}{c}0.00 \\
- \\
0.20\end{array}$ & Fourth & $\begin{array}{c}\text { More } \\
\text { then } \\
55 \%\end{array}$ & $\begin{array}{l}\text { Rapidly } \\
\text { Vanishes }\end{array}$ & $\begin{array}{l}\text { Unable } \\
\text { to track }\end{array}$ \\
\hline
\end{tabular}

Table 4. Measurement system class of monitor and their characteristics for different $r_{0}$ [23]. 
The first introduced factor is attenuation of process signals that determine into how many percentages can the measurement system attenuate the production process signal (to degrade the information provided by process variability). It means to attenuate the observed variance in comparison to the real variance. The interaction between the production process signals and the measurement system signals is visible in Fig.2., where on the $\mathrm{x}$-axis the intraclass correlation coefficient $\left(r_{0}\right)$ is shown and on the y-axis is signal strength in percentage.

The second important factor is the chance of detecting a 3standard error shift according to Western electric rules by the subgroup of ten parts [24]. In accordance to Wachsa [24], it is very important to detect the shift in production process, because when it is not done there is a risk of facing an error of type II, which means that the nonconformity part is evaluated as conformity part. It means that the regular chart has to detect the measurement above the UCL (upper control line) or LCL (lower control line), but it is not the case.

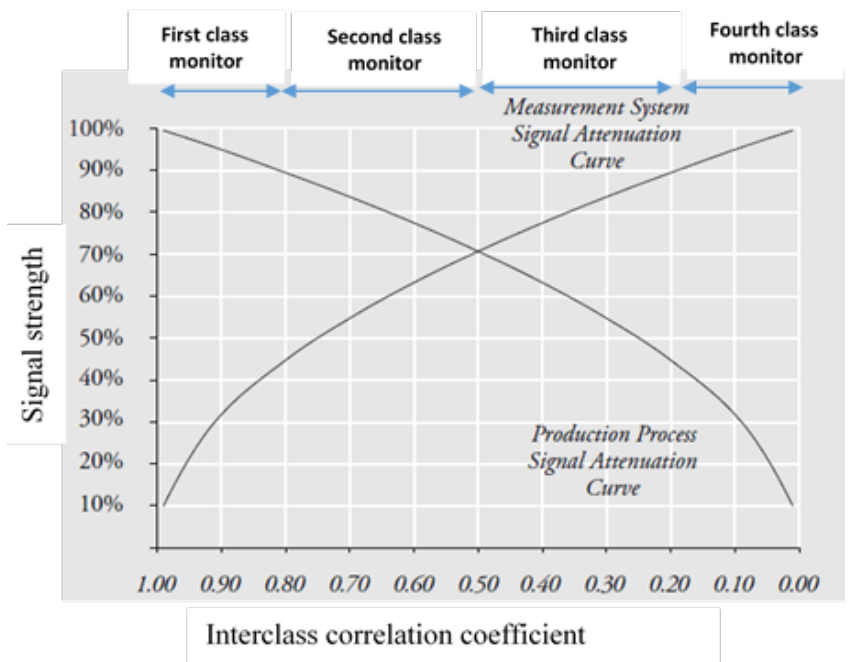

Fig.2. Attenuation of production process and measurement system signals.

The last introduced factor is linked with the chance to detect the process improvement (see the classification borders in Table 2.). The last column of Table 2 . shows how big must the process improvement or weakening be for the process to be moved from one class monitor into the other.

The analytical part of the honest GRR consists, similarly to the average and range method, of some systematically following steps. The first step is counting repeatability of variance component according to (12).

$$
\left(\hat{\sigma}_{p e}\right)^{2}=E V^{2}=\left(\frac{\overline{\bar{R}}}{d_{2}}\right)^{2}
$$

where,

$\overline{\bar{R}}$ - the average variation range of all operators repeated measurements for all parts,

$d_{2}$ - correction factor for values link to the distribution of average variation (see appendix C in MSA, AIAG guideline) [7]. It is necessary to look for this coefficient in the penultimate line, whereas $\mathrm{m}=$ number of repeated measurement trials. For $\mathrm{m}=3->d_{2}=1.69257$.

The second step is counting the variance component called reproducibility according to (13). $\bar{R}_{D I F F}$ is calculated the same as by the average and range method and it is according to the already mentioned (13).

$$
\left(\hat{\sigma}_{o}\right)^{2}=A V^{2}=\left\{\left[\left(\frac{\bar{R}_{D I F F}}{d_{2}}\right)\right]^{2}-\frac{o}{o . n \cdot r} \cdot\left(\hat{\sigma}_{p e}\right)^{2}\right\}
$$

For (13) apply:

$\mathrm{r}$ - number of measured parts,

$\mathrm{n}$ - number of repeated measurement trials,

$\mathrm{o}$ - number of operators,

$d_{2}$ - correction factor for values link to the distribution of average variation (see appendix C in MSA, AIAG guideline) [7]. It is necessary to look for this coefficient as g (number of subgroups) $=1$ (fixed factor) and $m$ (subgroup range) = number of operators (variable). For $\mathrm{m}=3$ (conducted measurement task) $\rightarrow d_{2}=1.91155$.

The next step is calculating the combined repeatability and reproducibility according to (14) and the total variation according to (15).

$$
\begin{gathered}
\left(\hat{\sigma}_{e}\right)^{2}=G R R^{2}=\left(\hat{\sigma}_{p e}\right)^{2}+\left(\hat{\sigma}_{o}\right)^{2} \\
\left(\hat{\sigma}_{x}\right)^{2}=T V^{2}=\left(\hat{\sigma}_{p}\right)^{2}+\left(\hat{\sigma}_{e}\right)^{2}
\end{gathered}
$$

Because the second power of the part variance is not known, it is necessary to calculate it according to (16).

where,

$$
\left(\hat{\sigma}_{p}\right)^{2}=P V^{2}=\left[\frac{R_{p}}{d_{2}}\right]^{2}
$$

$\mathrm{Rp}$ - the variation range from the measurement of arithmetic mean of the individual repeats for the individual subgroups of the parts.

$d_{2}-$ correction factor for values link to the distribution of average variation (see appendix C in MSA, AIAG guideline) [7]. It is necessary to look for this coefficient as g (number of subgroups) $=1$ (fixed factor) and $m$ (subgroup range) $=$ number of measured parts (variable). For $\mathrm{m}=10$ (No. of measured parts) $\rightarrow d_{2}=3.17905$.

The next step is calculating the percentage component of combined repeatability and reproducibility \% GRR (17), also the percentage component value of variance component repeatability (18) and reproducibility component (19).

$$
\begin{aligned}
\% G R R & =100 \cdot \frac{\left(\widehat{\sigma}_{e}\right)^{2}}{\left(\widehat{\sigma}_{x}\right)^{2}} \\
\% G R R & =100 \cdot \frac{\left(\widehat{\sigma}_{e}\right)^{2}}{\left(\widehat{\sigma}_{x}\right)^{2}} \\
\% A V & =100 \cdot \frac{\left(\widehat{\sigma}_{o}\right)^{2}}{\left(\widehat{\sigma}_{x}\right)^{2}}
\end{aligned}
$$

The intraclass correlation coefficient is calculated according to (20) and on its basis the measurement system is classified in one of four class monitors. 


$$
r_{0}=\frac{\left(\widehat{\sigma}_{p}\right)^{2}}{\left(\widehat{\sigma}_{x}\right)^{2}}
$$

The penultimate step is the process signals attenuation calculation (21).

$$
\text { attenuation of process signals }=1-\sqrt{r_{0}}
$$

The last step is calculating the process improvement detection according to (22), (23), and (24).

$$
\begin{aligned}
& C_{p 80}=\frac{U S L-L S L}{6 \cdot\left(\frac{\overline{\bar{R}}}{d_{2}}\right)} \cdot \sqrt{1-0.80} \\
& C_{p 50}=\frac{U S L-L S L}{6 \cdot\left(\frac{\overline{\bar{R}}}{d_{2}}\right)} \cdot \sqrt{1-0.50} \\
& C_{p 20}=\frac{U S L-L S L}{6 \cdot\left(\frac{\overline{\bar{R}}}{d_{2}}\right)} \cdot \sqrt{1-0.20}
\end{aligned}
$$

\section{GRR ANALYSES COMPARISON BASED ON RESULTS GAINED} BY TWO METHODS (AVERAGE AND RANGE METHOD AND THE HONEST GRR STUDY)

In this article subhead, the results of GRR analysis (see Table 5.) based on two methods are compared:

- average and range method,

- the honest GRR study.

The average and range method evaluate the measurement system as not acceptable, because the \% GRR $=33.41$ and is more than $30 \%$ and the ndc parameter has the value 3 , which is also not an acceptable value of the ndc parameter. The variability component called repeatability has the value $32.23 \%$, the reproducibility component is $8.81 \%$, the part variability component is $94.25 \%$. It means that by each variability component sum, the total variability is more than $100 \%$, which is a bit difficult to agree by mathematical rules. Reason for that is the counting variability component as standard deviation by AV \& GRR.

According to the honest GRR study the analyzed measurement system is evaluated as first-class monitor, because the intraclass correlation coefficient has reached the value 0.89 . Same as by the average and range method, each variability component can be defined separately. The variability component repeatability has a value of $10.38 \%$, the variability component reproducibility has a value of $0.78 \%$, the combined variability component repeatability and reproducibility has a value of $11.16 \%$. The total variability value is obtained by counting all partial components and is $100 \%$. The process signal attenuation will be $5.74 \%$ and the measurement system attenuation will be $94.26 \%$ (the observed process will be very similar to the real process). For the first class monitor measurement process there will be more than $99 \%$ probability of detecting the 3-standard deviation shift by number of subgroups 10 based on the Western Union rule No. I. The measurement system has the

\begin{tabular}{|c|c|}
\hline $\begin{array}{l}\text { Average and range method } \\
\text { (AIAG, MSA approach) }\end{array}$ & $\begin{array}{l}\text { The honest GRR study } \\
\text { (EMP approach) }\end{array}$ \\
\hline Variability component & Variability component \\
\hline$E V=0.041937$ & $\left(\hat{\sigma}_{p e}\right)^{2}=0.001759$ \\
\hline$A V=0.011500$ & $\left(\hat{\sigma}_{o}\right)^{2}=0.000132$ \\
\hline $\mathrm{GRR}=0.043486$ & $\left(\hat{\sigma}_{e}\right)^{2}=0.001891$ \\
\hline$T V=0.130196$ & $\left(\hat{\sigma}_{x}\right)^{2}=0.016951$ \\
\hline$P V=0.122719$ & $\left(\hat{\sigma}_{p}\right)^{2}=0.015060$ \\
\hline $\begin{array}{c}\% \text { of variability component } \\
\text { (counted as standard } \\
\text { deviation) }\end{array}$ & $\begin{array}{l}\% \text { of variability component } \\
\text { (counted as variance) }\end{array}$ \\
\hline $\begin{array}{l}G R R=100 \cdot \frac{0.043486}{0.130196} \\
=\mathbf{3 3 . 4 1}\end{array}$ & $\begin{array}{l}G R R=\left(\hat{\sigma}_{e}\right)^{2} \\
=100 \cdot \frac{0.0018902}{0.0169311} \\
=11.16\end{array}$ \\
\hline $\begin{array}{c}E V=100 \cdot \frac{0.041937}{0.130196}= \\
32.23\end{array}$ & $\begin{array}{l}E V=\left(\hat{\sigma}_{p e}\right)^{2} \\
=100 \cdot \frac{0.001759}{0.0169311} \\
=10.38\end{array}$ \\
\hline $\begin{array}{c}A V=100 \cdot \frac{0.011500}{0.130196}= \\
8.81\end{array}$ & $\begin{array}{l}A V=\left(\hat{\sigma}_{o}\right)^{2} \\
=100 \cdot \frac{0.0001315}{0.0169311} \\
=0.78\end{array}$ \\
\hline $\begin{array}{r}P V=100 \cdot \frac{0.122719}{0.130196} \\
=94.25\end{array}$ & $\begin{array}{l}P V=\left(\hat{\sigma}_{p}\right)^{2} \\
=100 \cdot \frac{0.0150409}{0.0169311} \\
=88.84\end{array}$ \\
\hline $\begin{array}{c}n d c=1.41 . \frac{0.122719}{0.043486}= \\
3.97=>3\end{array}$ & $r_{0}=\frac{0.0150409}{0.0169311}=\mathbf{0 . 8 9}$ \\
\hline
\end{tabular}
ability to track the process improvement up to $\mathrm{C}_{\mathrm{p} 80}$ where the value is 2.79 .
Table 5. Results of GRR analyses for the measured data in Table 1.

\section{CONCLUSIONS}

From the submitted study, the following can be concluded:

- the total variability by the average and range method (AIAG, MSA approach) will not give the value of $100 \%$. The confusion here is the fact that part to part, EV \& AV variations are expressed in percentage. Then there is expectation that the total variation will be $100 \%$.

- The honest GRR study (EMP approach) respects the basic percentage understanding and all variability components are getting the sum of $100 \%$. Reason for this is that the method is counting the variability components from variance.

How the perceptual components of variability are calculated by average and range method, this is explained in article [26] by Wheeler. To the fact of not getting the value of $100 \%$ by all variability components summation (MSA approach) point also Ermer in his article [28] or Pandiripalli in his submitted thesis [20]. In general, the honest GRR study provides extended information about the measurement 
system. Beyond partial variability components information, there is also information available regarding:

- process signal attenuation,

- measurement system attenuation,

- ability to detect the shift of 3 standard deviations by the subgroup of $n=10$

- the ability to track the process improvement or weakness. An interesting and recommended comparison of gauge repeatability and reproducibility methods is also available in the thesis of Stamm [19]. Nowadays, the MSA approach has a dominant position. Similar discussions are for example between the MSA and VDA5 approach. This discussion was highlighted in the article [28] by Dietrich. Also, in the case of MSA and the honest GRR study there is the fight about being the market leader for measuring system studies. And only the time will reveal the leading trend in measurement system analyses.

\section{ACKNOWLEDGEMENT}

Article has been written in connection with the project Students Grant Competition SP2017/147 and SP2017/149 financed by the Ministry of Education, Youth and Sports, and the Faculty of Mechanical Engineering VŠB-TUO.

\section{REFERENCES}

[1] Hart, R.F., Hart, K.M. (1994). The evaluation of a measurement system. Production and Inventory Journal, Fourth Quarter, 22-26.

[2] Antony, G.V., Knowles, G. (2000). A practical methodology for analyzing and improving the measurement system. Quality Assurance, 3 (3), 59-75.

[3] International Automotive Task Force. (2016). Automotive quality management system standard. $4^{\text {th }}$ Edition. IATF16949:2016.

[4] Chrysler Corporation, Ford Motor Company, General Motors Corporation (AIAG). (1998). Quality System Requirements. $3^{\text {rd }}$ Edition. QS-9000.

[5] Chrysler Corporation, Ford Motor Company, General Motors Corporation (AIAG). (2008). Advanced Product Quality Planning and Control Plan (APQP), Second Edition. AIAG.

[6] Hermans, J.E., Liu, Y. (2013). Quality management in the new product development: A PPAP approach. Quality - Innovation - Prosperity, 17 (2).

[7] Chrysler Corporation, Ford Motor Company, General Motors Corporation (AIAG). (2010). MSA Measurement Systems Analysis (MSA), Fourth Edition. AIAG.

[8] Wheeler, D.J. (2006). EMP III - Evaluating the Measurement Process \& Using Imperfect Data. SPC PRESS (Statistical Process Control).

[9] Verband der Automobileindustrie e.V. (2011). VDA 5 Vhodnost kontrolnich procesü, 2. vydanie. Praha, ČR: Česká společnost pro jakost.
[10] Klaput, P. (2014). Methodical approach to measurement system analyses. Dissertation Thesis, VŠB - Technical University of Ostrava, Faculty of Metallurgy and Materials Engineering. (in Czech)

[11] Dietrich, E., Schulze, A. (2003). Eignungsnachweis von Prüfprozessen. Carl Hanser Verlag.

[12] Kazerouni, A.M. (2009). Design and analyses of gauge R\&R studies: Making decision based on ANOVA method. International Journal of Mechanical, Aerospace, Industrial, Mechatronic and Manufacturing Engineering, 3 (4).

[13] Throne, J.L. (2008). Understanding Thermoforming. Carl Hanser Verlag.

[14] Rolls-Royce (2013). Measurement System Analyses : How-to Guide. Version 6.1. Rolls-Royce plc., 53.

[15] Healy, S., Wallace, M. (2011). Gage repeatability and reproducibility methodologies suitable for complex test systems in semi-conductor manufacturing. In Six Sigma Project and Personal Experiences. InTech.

[16] Minitab. (2010). Minitab guideline of methods and formulas. Version 16.1.1.0. Minitab Inc.

[17] Knowles, G., Vickers, G., Anthony, J. (2003). Implementing evaluation of the measurement process in an automotive manufacturer: A case study. Quality and Reliability Engineering International, 19 (5), 397-410.

[18] Dusharme, D. (2011). An Interview with Donald J. Wheeler. Quality Digest, May 2011.

[19] Stamm, S. (2013). A comparison of gauge repeatability and reproducibility methods. Dissertation Thesis, Indiana State University, USA.

[20] Pandiripalli, B. (2010). Repeatability and reproducibility studies: A comparison of techniques. Thesis, Wichita State University, USA.

[21] SAS Institute. (2013). SAS/QC 13.1 : User's Guide. Cary, NC, USA: SAS Institute Inc.

[22] BPI Consulting, LLC. (2014). Evaluating the Measurement Process - Part 1.

[23] Wheeler, D.J. (2009). An honest gauge R\&R study (rev.). In ASQ/ASA Fall Technical Conference, Manuscript No. 189.

[24] Wikimedia Foundation, Inc. Western electric rules. https://commons.wikimedia.org/wiki/File:Western_ele ctric_rules.svg.

[25] Wachs, S. How can an OC curve be used to manage the risk of undetected special causes? http://www.integralconcepts.com/docs/.

[26] Wheeler, D.J. (2016). Good data, bad data, and process behaviour charts. http://asq.org/statistics/ 2003/01/good-data-bad-data-and-process-behaviorcharts.pdf.

[27] Ermer, S.D. (2016). Improved gage R\&R measurement studies. Quality Progress, March 2006, 77-79.

[28] Dietrich, E. (2011). Wo liegen die Unterschiede? Vergleich von MSA and VDA Band 5. QZ, 56 (6), 3034. http://vda-qmc.de/fileadmin/redakteur/presse/QZ6 _11_Vergleich_von_MSA_und_VDA_Band_5.pdf. 
[29] Standards Department VW. (2012). Capability of measuring processes (Consideration of measuring uncertainty in test processes). Standard VW 10119.

[30] Krolczyk, J., Krolczyk, G., Legutko, S., Napiorkowski, J., Hloch, S., Foltys, J., Tama, E. (2015). Material flow optimization - a case study in automotive industry. Tehnički vjesnik - Technical Gazette, 22 (6), 14471456.
[31] Nieslony, P., Krolczyk, G.M., Wojciechowski, S., Chudy, R., Zak, K., Maruda, R.W. (2018). Surface quality and topographic inspection of variable compliance part after precise turning. Applied Surface Science, 434, 91-101.

Received October 10, 2017. Accepted February 14, 2018. 